\title{
How to Influence Government Policy with Your Research: Tips from Practicing Political Scientists in Government
}

\author{
Rick Farmer, Oklahoma House of Representatives
}

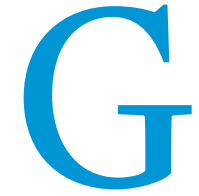

overnment policymakers rarely consult with academic experts before formulating policy positions. When policymakers do seek out academics, they are often attempting to justify a position they already hold, not searching for objective analysis. Academics could add much to the policy debate if they were more meaningfully engaged in the discussion.

The newly organized APSA Working Group on Practicing Politics met for the first time in Toronto during the 2009 Annual Meeting. The group includes a number of political scientists with full-time careers in government. One of the topics they chose to explore was how political scientists can persuade governments to better use their research findings.

This article discusses four aspects of communication between academic researchers and government officials. The first section addresses reasons that the two worlds fail to communicate-the clash of cultures. The second section offers reasons why political scientists should seek to communicate with policymakers-benefits to academics. The third provides some ways to keep policymakers informed of the availability of research products-getting policymakers' attention. And the fourth section offers some practical tips for communicating useful research findings to government decision makers-selling the sizzle.

\section{THE CLASH OF CULTURES: GETTING TENURED VS. GETTING REELECTED}

Political scientists conduct valuable research on topics debated in the halls of government. Unfortunately, governments are frequently oblivious to this work. The primary reasons that policymakers ignore academics are differences in culture built on differences in incentives (Gibbons et al. 2008).

The academic reward structure centers on tenure and promotion, and the primary demand is for publishable material. Publication requires rigorous research methods, months of data collection, careful analysis, precise explanation, and comprehensive writing. Administrations also reward faculty who acquire research grant funding. The standards for successful grant applications are similar to those of publication. Conference papers and other research productions are considered a step along the road to publication and require similar amounts of time and effort. Academics generally do not receive much credit from their institutions for providing information to policymakers, unless their efforts result in funding.

Rick Farmer is the director of the committee staff at the Oklahoma House of Representatives. Previously, he was an associate professor of political science at the University of Akron and a fellow in the Ray C. Bliss Institute of Applied Politics. He can be reached atrick@rickfarmer.net.
Academic incentives breed a culture of slowly developed, in-depth expertise in niche issues. Political scientists build an objective body of knowledge one study at a time. Taken as a whole, the research offers valuable insight, although any single study may not seem particularly relevant to a policymaker.

Policymakers have a completely different reward system. Elected officials are rewarded by gaining reelection, being elected to a higher office, or being selected by their peers as leaders within the party or the chamber. They benefit from getting out in front of an issue, recognizing an emerging concern, and proposing a solution. Not only must officials try to stay a step ahead of the demands of their constituency, but they are also constantly in competition with one another. As a result, they rarely can afford spending months to study an issue. When policymakers want an answer, they want it immediately. If a brief summary of a fullblown study is not readily available, a quick analysis will suffice (see Bardach 2005).

Given the luxury of time, many policymakers would enjoy reading the relevant research on a variety of topics. In the absence of that luxury, they must frequently seek support and justification for a preconceived idea. Their goal is to find policy solutions that meet their partisan predispositions and attract little controversy (Gibbons et al. 2008).

The problem, according to Mark Shafer of the Oklahoma Climatologic Survey (2006), is "the process, not the content," meaning the clash between the research process and the policy process. Jeffrey Henig (2009) demonstrates the clash of cultures between researchers and policymakers regarding charter schools. He illustrates how research is frequently misappropriated by policymakers and how researchers can get caught up in the policy debate.

\section{BENEFITS FOR ACADEMICS-WHY GETTING THROUGH TO GOVERNMENT BENEFITS YOU}

Despite the cultural challenges, effective communication with policymakers presents numerous advantages to academics. Some of these benefits are altruistic and others are self-interested. Among the most altruistic of reasons, policymakers need rigorous data analysis to make good decisions. Obviously, good decisions are in the interest of all. Another altruistic reason for open communication is to help establish and communicate best practices industry standards.

A slightly self-serving reason that political science researchers should want to communicate with policymakers is to create greater public awareness of the value of social science. The public and their elected officials have little appreciation for how political science research can and does affect their daily lives. To be effective, Mary Woolley (200o) says that scientists need to be vocally 
passionate about their work and the good it does for society. All three groups-social scientists, the public, and elected officialsbenefit when researchers actively explain the value of their work.

One less altruistic reason for presenting work to policymakers is that through research, some social scientists develop policy positions and the desire to influence relevant policy decisions. Supplying information to like-minded policymakers serves the purposes of both the researcher and the policymaker. Making oneself available to elected officials is beneficial, because these people frequently control university budget and research funds. Conducting research that they find useful is valuable when budgets are being determined.

Finally, effective communication of research builds the reputation of the researcher and the university. The currency of a university or research institute is its reputation. The stronger the reputation, the more students the institution can attract, the greater the funding opportunities available, and the more weight given to research findings. Communicating results in useful ways makes policymakers and the community at large more aware of the valuable work being conducted.

\section{GETTING POLICYMAKERS' ATTENTION-NETWORKING, NETWORKING, NETWORKING}

Researchers tend to be passive in their distribution of findings to policymakers (Spilsbury and Nasi 2006). Academic incentives encourage scholars to publish an article and move to the next project. At the point at which research is ready to be distributed to the public and policymakers, incentives have been met, so researchers do not make the additional effort necessary to notify policymakers of their work. Findings are published in a professional journal. Research colleagues are aware of it. Essential university administrators see the work on the scholar's vitae. Pursuing the next project is more important than wider distribution of the last one.

A few simple additional steps to make research more accessible to policymakers could produce a number of benefits. The first step is to get policymakers' attention. As with other marketing, the messages need to be brief, with the goal of grabbing enough attention to get the policymaker to ask for more information. A policymaker may not be interested in information on a particular topic until an event makes the issue salient to the public. Then, the policymaker will demand a lot of information quickly. Regularly highlighting the availability of research to policymakers and their staff will help them know where to turn when they need data or analysis. Former Governor Jim Edgar of Illinois makes a similar point. He offers several tips to academics seeking to influence policy, such as "use understandable language" and "keep it short" (see figure 1).

One of the most valuable resources on campus for marketing research is the university public relations department, whose primary mission is to build the reputation of the institution. These people are highly skilled at delivering messages to target groups. The university government relations office can also help distribute research findings to policymakers. A researcher who wants to see his or her work influence public decisions should engage these resources.

The more personal the contact, the more likely it will have an effect. Building personal networks with policymakers will enhance the likelihood of someone knowing that applicable research is available when the need arises. Sending faculty for sabbaticals or
Figure 1

Jim Edgar's Recommendations for

Communication between Political Scientists and Government Officials

- Be relevant

- Write in understandable terms

- Keep it short

- Build trust

- Identify key players, including staff

- Be available to serve on advisory commissions

- Encourage students to go into public service

Note. Derived from comments presented by former Illinois governor Jim Edgar to the 2010 State Politics and Policy Conference, Springfield, IL, June 3-5. For more information, see http://webcast2.uis.edu/multimedia/Archive/2010/ SPPCOldStateCapitol.html.

students for internships to policy-related venues and receiving policymakers as guest instructors are excellent ways to build personal networks. APSA's Congressional Fellowship Program can help facilitate academic and policymaking exchanges (American Political Science Association 2008). Engaging people who are directly involved in a policy area-such as a legislative committee chairman-is important. Building relationships with relevant staff in both the legislative branches and the executive agencies is imperative. Developing relationships with journalists is another way to attract the attention of both the public and policymakers. APSA's media relations staff can also be supportive (see Rajaee 2008).

A group of researchers working in a specific policy area can benefit from each other's reputations by forming an institute. This approach has been used very successfully by Michael Malbin and others at the Campaign Finance Institute (http://www.cfinst.org). Branding an institute and creating synergy among researchers raises awareness of the available data. Developing a directory of experts and distributing it to research consumers is another way to make them aware of whom to call when the need arises.

National nonpartisan governmental associations and think tanks are well connected to policymakers. Partnering with these groups in developing a research project adds gravitas to the project and ensures a distribution network for the findings. A successful example of this type of collaboration is the Joint Project on Term Limits, for which the National Conference of State Legislatures, the Council of State Governments, the State Legislative Leaders Foundation, a group of political scientists, and a funder joined forces. The results were distributed to legislators around the country in the form of a booklet entitled Coping with Term Limits: A Practical Guide. In addition, academics published two books and several journal articles from the data that were collected.

Maintaining contact with alumni can be helpful in this enterprise. Political science majors are scattered throughout the halls of government. Their respect and appreciation for their instructors can help promote the use of research from their institution.

Institutions should recognize the benefits of research dissemination to policymakers and alter the academic reward system to include such activities. In fact, most institutions appreciate faculty who raise the profile and enhance the reputation of the institution. Generally, those researchers are rewarded, even if outside 
the formal reward system. A publicly recognized expert is more likely to receive institutional research funds, plum appointments, salary increases, and promotions than one with equal academic accomplishments who is less publicly recognized. Universities could make the incentives for engaging in policy discussion more explicit.

Of course, policymakers should seek information. But like other economic maximizers, they are unlikely to keep abreast of available resources until they need them-when they want them immediately. It is incumbent upon researchers to keep policymakers and their staff aware of these resources, so that when they are needed, they can be easily found.

\section{SELLING THE SIZZLE-BE BRIEF, FOCUS ON THE MESSAGE}

Part of the clash of cultures between the university and policymaking spheres is the difference in communication formats. Policymakers look for brief explanations that capture the public's concerns and resolve their fears. Researchers develop in-depth explanations of how data were collected, why certain methods were chosen, and how conclusions were reached. In sales, a common cliché says to "sell the sizzle, not the steak," or to "sell the benefits, not the features." As distasteful as it may be to turn research results into a marketable product, effective communication in the policy arena is based on marketing principles. Tailoring the product to the consumer's need is essential.

According to David Pannell (2004), the key is to be brief and clear. Policymakers are not looking for the full explanation, they are looking for the "takeaways"-the sound bites and talking points. Researchers need not write the sound bites, but they must provide briefs that will allow the policymaker's staff to quickly find them.

When policy-relevant research is published, a researcher would do well to create a one- or two-page summary of his or her findings. This summary should focus on the benefits of a policy proposal. Keep the provision as simple as possible, but provide enough detail to be credible. The writing should use easy-to-understand language and terms that can be understood by people with no background or experience in the discipline or policy area. Policy options should be as concrete as the data will allow. Include enough data to make the relevant points. Focus on the message, not the method.

This summary can be distributed to relevant policymakers through numerous channels. If the policymaker needs the entire study, then he or she will request a copy. However, chances are that having the summary and knowing that a study backs it up is all that he or she will want.

Timing is everything. Distributing research findings as they are published will enhance the reputation of both the researcher and the institution and encourage policymakers to seek expertise when they need it. Be prepared for when they do need it. Respond quickly, or even take preemptive action. When a news headline breaks on a research topic, immediately issue a release of relevant issue papers. Do not wait for policymakers to call; rather put the word out that expertise on the topic is available.

\section{CONCLUSION}

Political scientists could provide policymakers with background research, policy options, analysis of various options, and best practices for managing many government issues. A clash of cultures prevents policymakers from paying attention to academic research. Politicians want quick, easily understood answers. Academics develop extended essays using terminology specific to the discipline. The rewards of making research accessible to policymakers can be considerable. Effective communication with policymakers requires marketing efforts beyond the publication of articles in prestigious journals.

Major corporations have research and development departments that are charged with keeping the company a step ahead of the competition and the market. Governments need such an arm. Unfortunately, the government pays scarce attention to the work of academics. Universities are full of researchers working for the betterment of society. Policymakers should pay more attention to the work done there, and universities should adjust academic incentives to include effective communication of research to policymakers.

\section{NOTE}

The Practicing Politics Working Group includes David Adamany, Carol Atkinson, Denise L. Baer, Christian Bueger, Amy Fletcher, Jorge Heine, Miguel Jerez-Mir, Karl Kurtz, Thomas Little, Elena V. McLean, Yin Ouynag, Theresa Reidy, Ken Rogerson, Meredith Reid Sarkees, Bojan Savic, Jeffrey W. Seifert, Stuart W. Shulman, Elton Skendaj, Marriah Star, Todd M. Szabo, Thiam Chye Tay, Franke Wilmer, John Wood, Irene Wu, and Yue Zange, many of whom contributed ideas to this article.

\section{REFEREN C ES}

American Political Science Association. 2008. "Engaging the World of Applied Politics." PS: Political Science and Politics 41 (4 suppl): 1.

Bardach, Eugene. 2005. A Practical Guide for Policy Analysis: The Eightfold Path to More Effective Problem Solving. 2nd ed. Washington, DC: CQ Press.

Gibbons, Philip, et al. 2008. "Some Practical Suggestions for Improving Engagement between Researchers and Policy-Makers in Natural Resource Management." Ecological Management and Restoration 9 (3): 182-86.

Henig, Jeffrey. 2009. Spin Cycle: How Research is Used in Policy Debates: The Case of Charter Schools. New York: Russell Sage.

Pannell, David J. 2004. "Effectively Communicating Economics to Policy-Makers." Australian Journal of Agriculture and Resources Economics 48: 535-55.

Rajaee, Bahram. 2008. "Advancing the Public Presence of Political Science." PS: Political Science and Politics 41 (3 suppl): 1.

Shafer, Mark. 2006. "Role of Scientists in Public Policy Decisions: The Case of Drought Planning." Paper presented at Was*Is Workshop, Oklahoma Climatological Survey, Norman, OK, April 18-20.

Spilsbury, Michael J., and Robert Nasi. 2006. "The Interface of Policy Research and the Policy Development Process: Challenges Posed to the Forestry Community." Forest Policy and Economics 8: 193-205.

Woolley, Mary. 200o. "Public Advocacy and Polling." Communicating Science and Technology in the Public Interest, 9. Washington, DC: National Science Foundation Board. Document no. NSB-oo-99. http://www.nsf.gov/nsb/publications/ landing/nsboog9.jsp. 


\section{Theodore H. White's Landmark Campaign Series}

Enduring Classics. Available for the First Time in Decades.

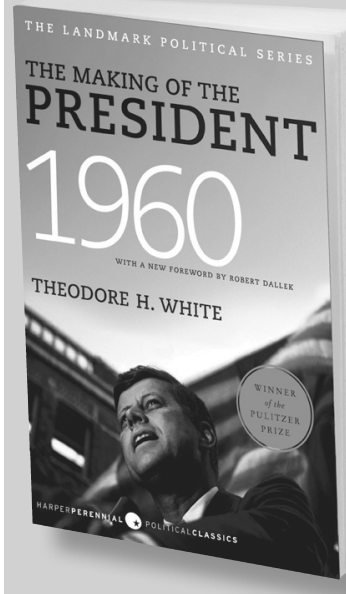

\section{The Making of} the President 1960

With a new

Foreword by

Robert Dallek

"White set a standard that neither television nor the Internet can replace."

Robert Dallek

978-0-06-190060-0 (pb)

$\$ 16.99$ (\$21.99 Can.)

432 pages

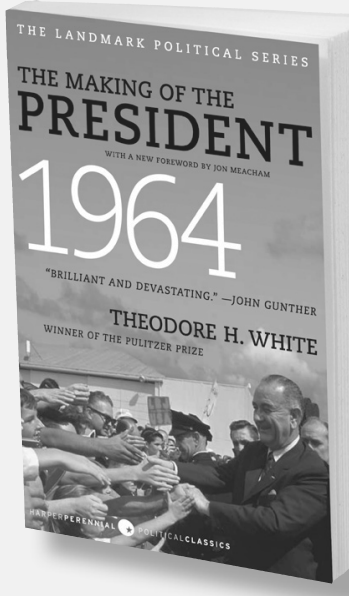

The Making of the President 1964

With a new

Foreword by

Jon Meacham

"White's genius was to deploy the skills of a novelist in the pursuit of journalism. The Making of the President 1964 resonates in our own time."

Jon Meacham

978-0-06-190061-7 (pb) $\$ 16.99$ (\$21.99 Can.) 496 pages

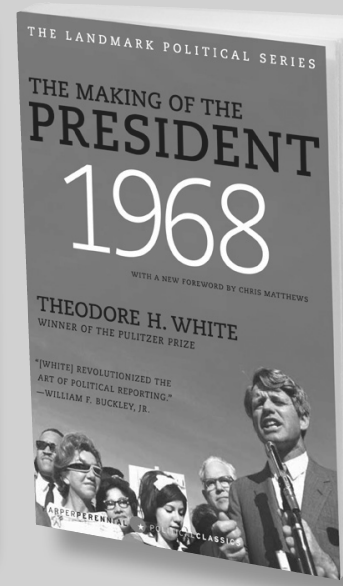

The Making of the President 1968

With a new

Foreword by

Chris Matthews

"By 1968, America was a land divided: hawk vs. dove, town vs. gown, long-haired against clean-cut, father against son. In The Making of the President 1968, White captures all this and more."

-Chris Matthews

\section{8-0-06-190064-8 (pb)} $\$ 16.99$ (\$21.99 Can.) 560 pages

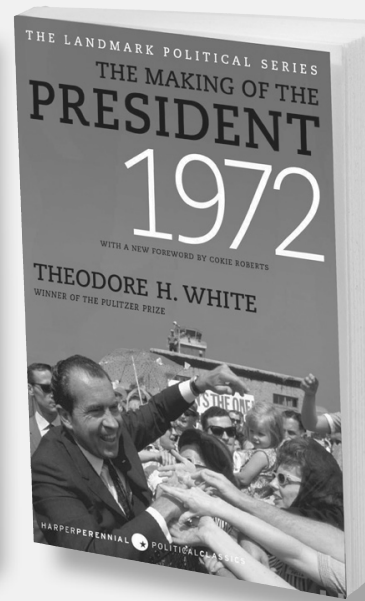

The Making of the President 1972

With a new

Foreword by

Cokie Roberts

“Juicy stories I had long since forgotten.... Makes an old-fashioned reporter like me yearn for 'the good old days,' when newspapers were profitable and network news was watched by fifty million."

Cokie Roberts

978-0-06-190067-9 (pb)

$\$ 16.99$ (\$21.99 Can.)

432 pages 